\title{
Do we Need Standardized, GMP-Compliant Cell Culture Procedures for Pre-Clinical In vitro Studies Involving Mesenchymal Stem/Stromal Cells?
}

Melanie L Hart ${ }^{1}$, Juliane Brun ${ }^{1}$, Katrin Lutz ${ }^{1}$, Bernd Rolauffs ${ }^{2}$ and Wilhelm K Aicher ${ }^{1 *}$

${ }^{1}$ Department of Urology, Eberhard Karls University, Germany

${ }^{2}$ Siegfried Weller Institute for Trauma Research, BG Trauma Clinic, Eberhard Karls University, Germany

\begin{abstract}
At present worldwide there are more than 350 clinical trials involving human Mesenchmal Stem/Stromal Cells (MSC). These trials involve the regenerative potential of hundreds of diseases or syndromes. However, only approximately $10 \%$ of the conditions explored are investigated in more than 10 clinical trials, while most of the maladies are investigated in 3 trials or less worldwide. In addition, the MSCs used in pre-clinical studies versus those used in the clinical trials are produced by variable procedures. In the majority of conditions under investigation the outcome of the studies is therefore cumbersome to evaluate. Standardizing in vitro cell culture procedures for definition and production of MSC could help to facilitate the evaluation of these cells in the clinical context, especially in those clinical trials that are minimally addressed. We advocate consistent Good Manufacturing Practice (GMP) compliant procedures for production of MSC in the context of all pre-clinical experiments, especially since clinically, GMP-compliant production of cells is the standard anyway.
\end{abstract}

Keywords: Stromal Cells; In vitro cell culture; Fibroblasts

\section{Introduction}

When our group first started to focus on regenerative medicine research in 1998, the knowledge regarding characteristics of many types of progenitor cells and true stem cells was sparse compared to the information available today. Back then many hospitals and laboratories had established standard operating procedures for isolation and direct application of various therapeutic cells, which was, at that time, mainly blood cells and Hematopoietic Stem Cells (HSC). Isolation, expansion and quality measures for chondrocytes, fibroblasts, keratinocytes and other cells destined for clinical applications after in vitro expansion were underway. Back then, therapeutic cells seemed sufficiently defined by their origin, in combination with one or two specific cellular and molecular features, including size, shape and expression of cell surface antigens (e.g., round, CD34+ non-adherent cells from bone marrow were considered bona fide HSC). However, it became clear that Mesenchymal Stem/Stromal Cells (MSC) ${ }^{1}$, also residing for instance in bone marrow, could not be sufficiently defined this way since they i) are detected in and isolated from many different types of tissues [1], ii) MSC share many cellular and molecular characteristics with other mesenchymal cells, including fibroblasts, smooth muscle cells, pericytes and others, especially after in vitro expansion, and iii) a defining epitope for all human MSC is not yet defined, although expression of CD271 (low affinity nerve growth factor receptor) and Tissue NonSpecific Alkaline Phosphatase (TNAP) define at least proliferation and differentiation competent subsets of human MSCs from bone marrow [2]. But expression of CD271 plus TNAP are not investigated in depth on MSC from other sources, nor are they confirmed as common indicators of human MSC [3-5].

\section{Mesenchymal Stem/Stromal Cells}

A major breakthrough in MSC research came from a study in 1999 that reported that human bone marrow-derived MSC expressed cell surface markers SH2 (also known as CD105, endoglin, or TGF- $\beta$ receptor) and $\mathrm{SH} 3$ (also known as $\mathrm{CD} 73$, or ecto-5'-nucleotidase)

${ }^{1}$ Recently the term "mesenchymal stromal cells" was suggested to replace the term "mesenchymal stem cells", since MSCs do not quite meet all requirements to qualify as a true stem cell.
[6]. These phenotypic markers later became part of the norm for characterization of MSC and were even declared as part of the minimal set of standard criteria which would allow a uniform characterization of MSC and facilitate exchange of data among investigators by the International Society for Cellular Therapy (ISCT) consensus conference in 2006 [3]. From that point, expression of CD73, CD90, CD105 and lack of hematopoietic cells surface markers was used to define MSC even though the source of MSC was so variable $[3,7,8]$. But the seemingly same type of cell was later described and isolated from many human organs including vascularized tissues and even nonvascularized tissues, and these cells were also termed MSC [1,3-5,8-11]. Thus MSC are produced from bone marrow (bmMSC), adipose tissue (at MSC or adipose derived stem cells: ADSC), the placenta (pMSC), Wharton's Jelly (wjMSC) from the umbilical cord and many other organs and tissues, and at present are all considered simply MSC [12].

Meanwhile it has been noted that MSC from different sources differ quite significantly in their gene and protein expression patterns, and thus in their physiological characteristics [7,13-17]. Studies on human MSC from bone marrow or placenta even revealed functionally distinct subsets of MSC within the bulk population from the same source [2,18]. Accordingly, chondrocytes were derived mainly from the CD271 ${ }^{+} \mathrm{TNAP}^{+} \mathrm{CD} 56^{+}$subset of human bmMSC, whereas adipocytes were generated from the $\mathrm{CD} 271^{+} \mathrm{TNAP}^{+} \mathrm{CD} 56^{-}$subset [2]; and expression of CD146 correlated with the osteogenic differentiation potential of a subpopulation of human pMSC $[16,18]$. This suggests that we probably should define the population of MSC included in preclinical research more stringently prior to initiation of clinical trials.

*Corresponding author: Wilhelm K Aicher, Department of Urology, Eberhard Karls University, Tuebingen, Germany, Tel: +49 7071298 7020; Fax: +49 7071292 5072; E-mail: kfo273@med.uni-tuebingen.de

Received March 05, 2014; Accepted March 24, 2014; Published March 26, 2014

Citation: Hart ML, Brun J, Lutz K, Rolauffs B, Aicher WK (2014) Do we Need Standardized, GMP-Compliant Cell Culture Procedures for Pre-Clinical In vitro Studies Involving Mesenchymal Stem/Stromal Cells? J Tissue Sci Eng 5: 135. doi:10.4172/2157-7552.1000135

Copyright: ( 2014 Hart ML, et al. This is an open-access article distributed under the terms of the Creative Commons Attribution License, which permits unrestricted use, distribution, and reproduction in any medium, provided the original author and source are credited. 
The definition of a MSC set by ISCT consensus conference in 2006 is an important and significant step towards this goal, but does not seem to be sufficient to define the functionally different subsets described for example in human bmMSC $[3,19]$.

\section{All MSC are Equal, but Some are More Un-equal than Others...}

Besides the phenotypic differences noted among human MSC briefly mentioned above, significant variations in the differentiation potential of human MSC have also been described at length [3-6]. This differentiation potential motivated researchers and clinicians to consider MSC for various forms of clinical therapy. But in some of the pre-clinical studies towards this goal some aspects were not regarded in depth. We would like to discuss these issues in the context of muscle regeneration. For example: What is the efficacy of differentiation of MSCs to become, for example, smooth muscle cells? Do all bmMSCs expanded in vitro become smooth muscle cells, or do some cells, for instance the $\mathrm{CD} 271^{+} \mathrm{TNAP}^{+} \mathrm{CD} 56^{+}$subset, differentiate along a chondrogenic and osteogenic lineage of differentiation even under myogenic differentiation conditions? Is it sufficient to detect only the expression of mRNA or proteins associated with smooth muscle cells by RT-PCR, quantitative RT-PCR or immune blotting? Both technologies allow a quantitative evaluation of steady state transcript and protein amounts in the cells investigated. Then again an elevated expression of smooth muscle cell markers could be due to a mixed population of MSC where just a few cells have undergone the intended differentiation, or may be due to a slight elevation of these genes in all cells, without significant differentiation of the MSC in this direction. Therefore do we have to include immune histochemistry or flow cytometry to determine the percentage of cells differentiated along the lineage expected? Can mix populations of MSC or only slightly activated but not differentiated MSC be utilized in therapy?

The experimental differentiation of MSC toward the smooth muscle lineage has been described in the literature using different human cell sources, including bone marrow, adipose tissue, and placenta [2027]. However, various media was used for expansion of MSC prior to myogenic differentiation including DMEM (7 studies) DMEM low glucose (2 studies), a-MEM ( 3 studies), Media-199 (1 study), Bullet Kit (1 study), or an undefined medium enriched with Epidermal Growth Factor (EGF) and Platelet Derived Growth Factor-BB (PDGF-BB, 1 study). Furthermore, the MSC expansion media was enriched with various percentages of FBS 2\% (1 study), 10\% (13 studies), 13\% (1 study) or $15 \%$ (1 study) [28]. Supplementation of antibiotics and other components varied as well. However, according to the regulations of the European Medicines Agency (EMA) and Federal Drug Administration (FDA), use of FBS is not acceptable ${ }^{2}$ or significantly restricted ${ }^{3}$ in any stage of production of cells for a clinical application [29]. Therefore conclusion on the therapeutic potential of human MSC expanded under experimental and very variable techniques and in media containing xenobiotic serum such as FBS or other xenobiotic supplements should be drawn with outmost care.

Furthermore, for differentiation of MSC into smooth muscle cells rather diverse cocktails of stimuli were reported. Some studies reported induction of smooth muscle differentiation with TGF- $\beta$ and serum, while others used a combination of TGF- $\beta$, ascorbic acid, and PDGF [20-30,22]. One protocol added EGF-1, heparin, corticosteroids, and plated the MSC at $75 \%$ confluency on fibronectin coated plates, while

${ }^{2}$ in the case of the European Medicines Agency: http://www.ema.europa.eu/ema ${ }^{3}$ in the case of the US Federal Drug Administration (FDA): http://www.fda.gov another group plated the MSC on type I collagen and used TGF- $\beta$ and ascorbic acid for induction of differentiation [25]. Again, quite variable protocols were reported for induction of smooth muscle cell differentiation. This must be taken into account when it comes to an evaluation of the differentiation efficacy or the clinical potential of such cells.

Moreover, for detection of myogenic differentiation of MSC the expression of smooth muscle myogenic markers was investigated on a transcriptional level by RT-PCR, and on the protein level by immune fluorescence and/or by immune blotting. The marker genes investigated include $a$-smooth muscle actin, calponin, smooth muscle myosin heavy chain, transgelin and others [28]. But most studies investigating MSC and myogenesis in a pre-clinical context did not consider that smooth muscle cells appear in vivo and in vitro as a continuum of proliferative and contractile phenotypes [31]. And these phenotypes express a-smooth muscle actin, calponin, smooth muscle myosin heavy chain, transgelin and other myogenic markers at quite different levels [31]. However, protocols to preferably produce a proliferative or contractile cell are not yet at hand, but in a clinical context it may be beneficial to know if a contractile, proliferative, or perhaps mixed phenotype would function better in situ.

As present it seems that many laboratories proceed in their research with quite variable cells (bulk MSC or defined subsets), from different sources (e.g., bone marrow, adipose tissue, and so on), and in most cases with alterable, non-GMP-compliant media and myogenic induction protocols (e.g. xenobiotic serum). How can we define the optimal type of MSC and the best procedures for future cell based therapies with all the variables discussed above?

\section{Human MSC in a Pre-Clinical and in a Clinical Context}

For future pre-clinical studies it might be important to establish methods that are fully compliant with EMA and FDA regulations, at least for the expansion and differentiation of the MSC [32]. According to a recent internet search (www.clinicaltrials.gov), the therapeutic potential of bulk MSC has been explored in the meantime for a variety of diseases and conditions in clinical studies worldwide (Figure 1). In November 2012, 252 clinical studies were registered for use of MSC in patients. Most studies were dedicated to musculo-skeletal diseases, ischemia, the central nervous system and different autoimmune diseases [33]. In February 2014, 378 clinical trials using MSC, and on 24th March 2014, 457 studies were registered (www.clinicaltrials.gov, search word "human MSC"). This number does not include trials with other types of progenitor- or stem cells (March 2014: 4385 registered

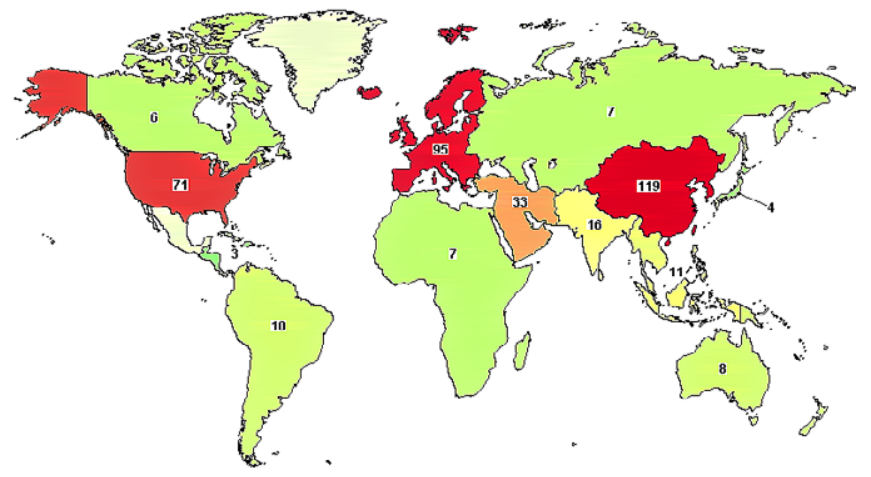

Figure 1: Registered clinical trials involving MSC in February 2014 source: www.clinicaltrials.gov; search key word: Mesenchymal Stem Cells or MSC. 
trials). At present China is leading the research in terms of clinical MSC trials (Figure 1). In most of the trials the regenerative potential of human MSC was mainly associated with their production of paracrine factors to modulate immune responses or to influence immune cells [17,34-36]. This includes suppression of tissue rejection upon organ transplantation $[37,38]$. But in other clinical studies secretion of paracrine factors by MSC supported tissue regeneration, wound healing, and (re-) vascularization [39-42].

From more than 500 conditions/diseases/entities listed in the registry of open MSC studies (www.clinicaltrials.gov), only 54 were investigated in greater than 10 trials by various research institutions or hospitals. For example studies investigating musculo-skeletal conditions/diseases/entities, yielded registered 63 clinical trials (Figure 2); for ischemic entities 55 clinical trials, for gastrointestinal indications 52 clinical trials, and for illnesses of the central nervous system 48 clinical trials are listed, respectively. In these cases, the statistical power is sufficient to evaluate and compare the results, even if a wide variety type of MSC and protocols were employed. But for most conditions, diseases or symptoms to be targeted by MSC, less than 3 trials are registered, and on average only 5 registered trials worldwide are dedicated to a given disorder, degeneration or problem (Figure 2). In such cases the variations, for example, in preparation of MSC, in protocols, including expansion, differentiation, quality measures, and application techniques, may make it difficult to evaluate the outcome.

To reduce at least one level of variability in a given pre-clinical situation, standardization of cell culture experiments that adhere to Good Manufacturing Practice (GMP) guidelines could help to reduce the variance of boundary conditions, and thus disburden the interpretation of clinical outcome of MSC-dependent studies. GMPcompliant production of cells includes i) the preparation and expansion of cells in media that do not contain xenobiotic components such as bovine serum, but use for instance human plasma or serum instead,

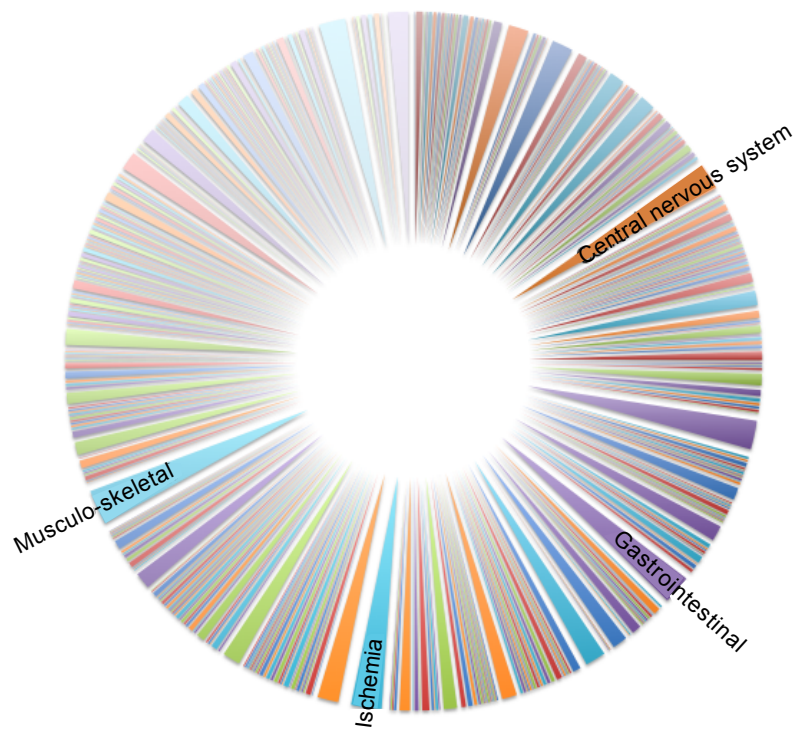

Figure 2: Number of trials addressing an entity, disease or other condition world-wide (in 2/2014). Clinical studies involving MSC were grouped according to the entity targeted, and 4 disciplines stick out from all studies: studies targeting the central nervous stystem (48 trials), gastrointestinal (52 studies), musculo-skeletal ( 63 studies) and circulatory/ischemic ( 55 studes) problems Most other entities are investigated by 3 or less trials world-wide, presented by the many very narrow slices. Data extracted from: www.clinicaltrials.gov; search key word: mesenchymal stem cells or MSC. ii) the definition of all steps and manipulations of the cell production in Standard Operating Procedures (SOP) from their isolation from the patient to the implantation, iii) research on the quality of the product including its features (e.g., phenotype), potency (e.g., differentiation capacity or cytokine production), purity (including sterility), iv) detailed records on all procedures applied during production of the cells, and v) storage of back-up samples for follow-up research eventually, and data storage for several years. In addition, the enrichment of MSC for instance by antibodies or other reagents to generate defined subsets of cells prior to their entry into clinical investigations may improve the efficacy of treatment. Based on the state-of-the-art results we conjecture that more consistent phenotypes of MSC employed in pre-clinical studies in combination with GMP-compliant protocols for production of the cells, will yield more harmonic outcomes overall.

In addition, for clinical applications cell banking, again under appropriate conditions, is an issue as well. Cell banking is a complex problem by itself and therefore cannot be discussed commensurably in this review, but needs a paper of its own [43-45].

\section{Conclusion}

Mesenchymal stem cells provide huge opportunities to initiate, facilitate or pursue processes of wound healing and tissue regeneration or to halt degenerative processes. But at present the huge opportunities are reflected by huge variations in the protocols employed in the studies published. Standardizing at least the procedures for definition, isolation, expansion and differentiation of MSC will facilitate the evaluation of outcome of pre-clinical and clinical studies, especially when the number of trials for a given syndrome under way or scheduled in the future, is or will be as low as 3-8 trials per illness, which, at present, is the majority of registered trials involving MSC.

\section{References}

1. Covas DT, Panepucci RA, Fontes AM, Silva WA Jr, Orellana MD, et al (2008) Multipotent mesenchymal stromal cells obtained from diverse human tissues share functional properties and gene-expression profile with CD146+ perivascular cells and fibroblasts. ExpHematol 36: 642-654.

2. Battula VL, Treml S, Bareiss PM, Gieseke F, Roelofs H, et al. (2009) Isolation of functionally distinct mesenchymal stem cell subsets using antibodies against CD56, CD271, and mesenchymal stem cell antigen-1. Haematologica 94: 173184.

3. Dominici M, Le Blanc K, Mueller I, Slaper-Cortenbach I, Marini F, et al. (2006) Minimal criteria for defining multipotent mesenchymal stromal cells. The International Society for Cellular Therapy position statement. Cytotherapy 8: 315-317.

4. Parolini O, Alviano F, Bergwerf I, Boraschi D, De Bari C, et al. (2010) Toward Cell Therapy Using Placenta-Derived Cells: Disease Mechanisms, Cell Biology, Preclinical Studies, and Regulatory Aspects at the Round Table. Stem Cell Dev 19: 143-154

5. Zuk PA, Zhu M, Mizuno H, Huang J, Futrell JW, et al. (2001) Multilineage cells from human adipose tissue: implications for cell-based therapies. Tissue Eng 7: 211-228.

6. Pittenger MF, Mackay AM, Beck SC, Jaiswal RK, Douglas R, et al. (1999) Multilineage potential of adult human mesenchymal stem cells. Science 284 143-147.

7. Aicher WK, Bühring HJ, Hart M, Rolauffs B, Badke A, et al. (2011) Regeneration of cartilage and bone by defined subsets of mesenchymal stromal cells-potential and pitfalls. Adv Drug Deliv Rev 63: 342-351.

8. Zannettino AC, Paton S, Arthur A, Khor F, Itescu S, et al. (2008) Multipotential human adipose-derived stromal stem cells exhibit a perivascular phenotype in vitro and in vivo. J Cell Physiol 214: 413-421.

9. Horwitz EM, Le Blanc K, Dominici M, Mueller I, Slaper-Cortenbach I, et al (2005) Clarification of the nomenclature for MSC: The International Society for Cellular Therapy position statement. Cytotherapy 7: 393-395. 
Citation: Hart ML, Brun J, Lutz K, Rolauffs B, Aicher WK (2014) Do we Need Standardized, GMP-Compliant Cell Culture Procedures for Pre-Clinical In vitro Studies Involving Mesenchymal Stem/Stromal Cells? J Tissue Sci Eng 5: 135. doi:10.4172/2157-7552.1000135

10. Alsalameh $S$, Amin R, Gemba T, Lotz M (2004) Identification of mesenchymal progenitor cells in normal and osteoarthritic human articular cartilage. Arthritis Rheum 50: 1522-1532.

11. De Bari C, Dell'Accio F, Vandenabeele F, Vermeesch JR, Raymackers JM, et al. (2003) Skeletal muscle repair by adult human mesenchymal stem cells from synovial membrane. J Cell Biol 160: 909-918.

12. Crisan M, Yap S, Casteilla L, Chen CW, Corselli M, et al. (2008) A perivascula origin for mesenchymal stem cells in multiple human organs. Cell Stem Cell 3: $301-313$.

13. Carvalho MM, Teixeira FG, Reis RL, Sousa N, Salgado AJ (2011) Mesenchyma stem cells in the umbilical cord: phenotypic characterization, secretome and applications in central nervous system regenerative medicine. Curr Stem Cell Res Ther 6: 221-228.

14. Hsieh JY, Wang HW, Chang SJ, Liao KH, Lee IH, et al. (2013) Mesenchymal Stem Cells from Human Umbilical Cord Express Preferentially Secreted Factors Related to Neuroprotection, Neurogenesis, and Angiogenesis. PLoS One 8: e72604.

15. Limbert C, Ebert R, Schilling T, Path G, Benisch P, et al. (2010) Functional signature of human islet-derived precursor cells compared to bone marrowderived mesenchymal stem cells. Stem Cells Dev 19: 679-691.

16. Pilz GA, Ulrich C, Ruh M, Abele H, Schafer R, et al. (2011) Human term placenta-derived mesenchymal stromal cells are less prone to osteogenic differentiation than bone marrow-derived mesenchymal stromal cells. Stem Cells Dev 20: 635-646.

17. Ribeiro A, Laranjeira P, Mendes S, Velada I, Leite C, et al. (2013) Mesenchyma stem cells from umbilical cord matrix, adipose tissue and bone marrow exhibit different capability to suppress peripheral blood B, natural killer and T cells. Stem Cell ResearchTher 4: 125

18. Ulrich C, Rolauffs B, Abele H, Bonin M, Nieselt K, et al. (2013) Low osteogenic differentiation potential of placenta-derived mesenchymal stromal cells correlates with low expression of the transcription factors Runx2 and Twist2. Stem Cells Dev 22: 2859-2872.

19. Bühring HJ, Treml S, Cerabona F, de Zwart P, Kanz L, et al. (2009) Phenotypic characterization of distinct human bone marrow-derived MSC subsets. Ann N Y AcadSci 1176: 124-134.

20. Gong Z, Calkins G, Cheng EC, Krause D, Niklason LE (2009) Influence of culture medium on smooth muscle cell differentiation from human bone marrow-derived mesenchymal stem cells. Tissue Eng Part A 15: 319-330.

21. Narita $Y$, Yamawaki A, Kagami H, Ueda M, Ueda $Y$ (2008) Effects of transforming growth factor-beta 1 and ascorbic acid on differentiation of human bonemarrow-derived mesenchymal stem cells into smooth muscle cell lineage. Cell Tissue Res 333: 449-459.

22. Tian H, Bharadwaj S, Liu Y, Ma H, Ma PX, et al. (2010) Myogenic differentiation of human bone marrow mesenchymal stem cells on a 3D nano fibrous scaffold for bladder tissue engineering. Biomaterials 31: 870-877.

23. Williams C, Xie AW, Emani S, Yamato M, Okano T, et al. (2012) A comparison of human smooth muscle and mesenchymal stem cells as potential cell sources for tissue-engineered vascular patches. Tissue Eng Part A 18: 986-998.

24. Harris LJ, Abdollahi H, Zhang P, Mcllhenny S, Tulenko TN, et al. (2011) Differentiation of adult stem cells into smooth muscle for vascular tissue engineering. J Surg Res 168: 306-314

25. Rodríguez LV, Alfonso Z, Zhang R, Leung J, Wu B, et al. (2006) Clonogenic multipotent stem cells in human adipose tissue differentiate into functional smooth muscle cells. ProcNatlAcadSci U S A 103: 12167-12172.

26. Wang HJ, Chuang YC, Chancellor MB (2011) Development of cellular therapy for the treatment of stress urinary incontinence. IntUrogynecol J 22: 1075-1083.

27. Chou MT, Chang SN, Ke C, Chang HI, Sung ML, et al. (2010) The proliferation and differentiation of placental-derived multipotent cells into smooth muscle cells on fibrillar collagen. Biomaterials 31: 4367-4375

28. Neumayer KMH (2013) Myogenic differentiation potential of human mesenchymal stromal cells. Medical and Pharmaceutical Biotechnology. Krems: Krems IMC University of Applied Sciences.

29. van der Valk J, Brunner D, De Smet K, FexSvenningsen A, Honegger P, et al (2010) Optimization of chemically defined cell culture media--replacing fetal bovine serum in mammalian in vitro methods. Toxicol In vitro: 24: 1053-1063.
30. Ross JJ, Hong Z, Willenbring B, Zeng L, Isenberg B, et al. (2006) Cytokineinduced differentiation of multipotent adult progenitor cells into functional smooth muscle cells. J Clin Invest 116: 3139-3149.

31. Rensen SS, Doevendans PA, van Eys GJ (2007) Regulation and characteristics of vascular smooth muscle cell phenotypic diversity. Neth Heart J 15: 100-108.

32. Felka T, Schäfer R, deZwart P, Aicher WK (2010) Animal serum- free differentiation of human mesenchymal stem cells. Cytotherapy 12: 143-153.

33. Kramer J, Dazzi F, Dominici M, Schlenke P, Wagner W (2012) Clinical perspectives of mesenchymal stem cells. Stem Cells Int 2012: 684827.

34. Aggarwal S, Pittenger MF (2005) Human mesenchymal stem cells modulate allogeneic immune cell responses. Blood 105: 1815-1822.

35. Opitz CA, Litzenburger UM, Lutz C, Lanz TV, Tritschler I, et al. (2009) Toll-like receptor engagement enhances the immunosuppressive properties of human bone marrow-derived mesenchymal stem cells by inducing indoleamine-2,3dioxygenase-1 via interferon-beta and protein kinase R. Stem cells 27: 909919.

36. Sudres M, Norol F, Trenado A, Grégoire S, Charlotte F, et al. (2006) Bone marrow mesenchymal stem cells suppress lymphocyte proliferation in vitro but fail to prevent graft-versus-host disease in mice. J Immunol 176: 7761-7767.

37. Peng Y, Ke M, Xu L, Liu L, Chen X, et al. (2013) Donor-derived mesenchymal stem cells combined with low-dose tacrolimus prevent acute rejection afte renal transplantation: a clinical pilot study. Transplantation 95: 161-168.

38. Tan J, Wu W, Xu X, Liao L, Zheng F, et al. (2012) Induction therapy with autologous mesenchymal stem cells in living-related kidney transplants: a randomized controlled trial. JAMA 307: 1169-1177.

39. Boomsma RA, Geenen DL (2012) Mesenchymal stem cells secrete multiple cytokines that promote angiogenesis and have contrasting effects on chemotaxis and apoptosis. PLoS One 7: e35685

40. Chen L, Tredget EE, Wu PY, Wu Y (2008) Paracrine factors of mesenchyma stem cells recruit macrophages and endothelial lineage cells and enhance wound healing. PLoS One 3: e1886.

41. Garcia-Arranz M, Gregorio SA (2012) Phase II clinical trial to study feasibility and Safety of the expanded autologous MSC derived from adipose tissue for the local feminine stress urinary incontinence.

2. Rackwitz L, Eden L, Reppenhagen S, Reichert JC, Jakob F, et al. (2012) Stem cell- and growth factor-based regenerative therapies for avascular necrosis of the femoral head. Stem Cell Res Ther 3: 7.

43. Perry BC, Zhou D, Wu X, Yang FC, Byers MA, et al. (2008) Collection, cryopreservation, and characterization of human dental pulp-derived mesenchymal stem cells for banking and clinical use. Tissue Eng Part C Methods 14: 149-156.

44. Stacey G (2012) Banking stem cells for research and clinical applications. Prog Brain Res 200: 41-58.

45. Thirumala S, Goebel WS, Woods EJ (2009) Clinical grade adult stem cell banking. Organogenesis 5: 143-154. 